\title{
Field Study of Riparian Zone along Sarawak River at Bintawa, Kuching
}

\author{
Darrien Y.S. Mah and Allan P.P. Pui
}

Department of Civil Engineering, Faculty of Engineering, Universiti Malaysia Sarawak

Date Received: $9^{\text {th }}$ February 2015

Date Published: $30^{\text {th }}$ April 2015

\begin{abstract}
Natural riparian zones are increasingly valued in recent years as they provide a variety of beneficial functions to the environment and possess substantial economic value. In this regard, it is necessary to call for simultaneous protection of the environment and promotion of economic growth. In this writing, a field methodology is presented for the purpose of riparian wetland conservation; it is used to investigate the riparian health through studying vegetation cover, human activities and groundwater table. Healthy riparian zones can be achieved through the balancing of riverbank human activities with maintaining the functionality of wetlands, which can be done by assessing the groundwater level a nd the amount of lush vegetation. A functioning riparian zone is found with a mean of $12 \%$ human activities in the range of 0 to $17.86 \%$, within an area along the water edge measuring $100 \mathrm{~m} \times 100 \mathrm{~m}$. It is only natural that the higher the percentage of the wetland vegetation that is flourishing, the more the riparian zone is functioning well.
\end{abstract}

Keywords: Anthropogenic, Ecosystem, Floodplain, Riverbank, Urbanisation, Wetlands.

\section{BACKGROUND}

A

riparian zone is an area of transition between land and water [1]. It supports some of the most productive ecosystems as rivers are conduits to support a diverse selection of vegetation and wildlife [2]. In most parts of the world, riparian zones are extensively modified. When humans live close to streams, riparian zones are exposed to exploitation and alteration. This disturbance would begin to affect the delicate ecosystem balance that once existed naturally. The frequent and intense disturbances due to increasing human activities may create problems in maintaining the balance of ecosystem functions.

One important question is raised: "How much change can riparian zones tolerate in relation to human disturbances?" In response to that, studies are therefore needed to understand the implications of human-related activities on riparian zones [3]. Indicators can be developed to gauge the health of wetland ecosystems [4].

\section{METHODS}

This study has been carried out at Bintawa, located east of Kuching City. Bintawa is a light industrial estate sandwiched between the Sarawak River in the north and residential houses along its southern fringe. The main objective is to detect and assess changes of this stretch of riparian zone. The selected location is suitable for this study due to the presence of natural vegetation and human disturbances within the riparian zone. Three selected indicators-human activities, vegetation cover and groundwater table can be easily assessed. Hence, with the known conditions and functions of the existing riparian zone, these three indicators - vegetation cover, groundwater table and human activities within the system provide clues about the impacts of human disturbances on the riparian conditions. Figure 1 below shows how the assessment is done.

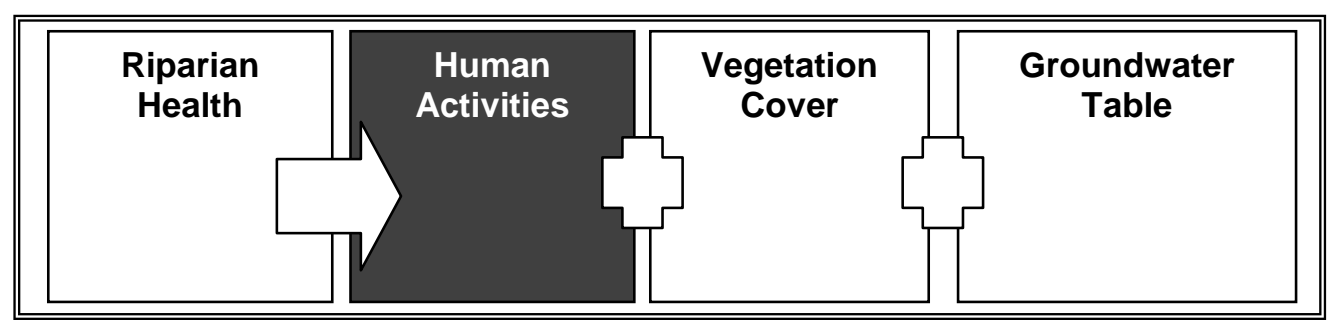

Figure 1: Framework to Assess Human Impacts on Riparian Health

Darrien Y. S. Mah is with the Department of Civil Engineering, Universiti Malaysia Sarawak, 94300 Kota Samarahan, Sarawak, Malaysia. (Tel: 082583207, Fax: 082-583409, e-mail: ysmah@ @eng.unimas.my).

Allan P.P. Pui is a Civil Engineer who graduated from the Faculty of Engineering, Universiti Malaysia Sarawak. 


\section{UNIMAS e-Journal of Civil Engineering}

For this study, $100 \mathrm{~m} \times 100 \mathrm{~m}$ sampling plots are delineated to assess vegetation cover and human activities, a method common to biologists [5]. Although the range of riparian width varies, $100 \mathrm{~m}$ x $100 \mathrm{~m}$ plots are preferred rather than smaller plots as the former cover adequately the vegetation and human activities along the river edge. Twenty-three (23) plots are marked out along the riverbank, as shown in Figure 2. Assessment is basically carried out by analysing the spatial relationships between the earth's features and events [6]; this is done by utilising the Environmental System Research Institute (ESRI)'s ArcView GIS software. Based on the layout of vegetation cover and human activities within the sampling plots such as concrete drains, roads, parking lots and buildings, the GIS produces a mapping of distribution, abundance and interspersion of the two land uses [7].

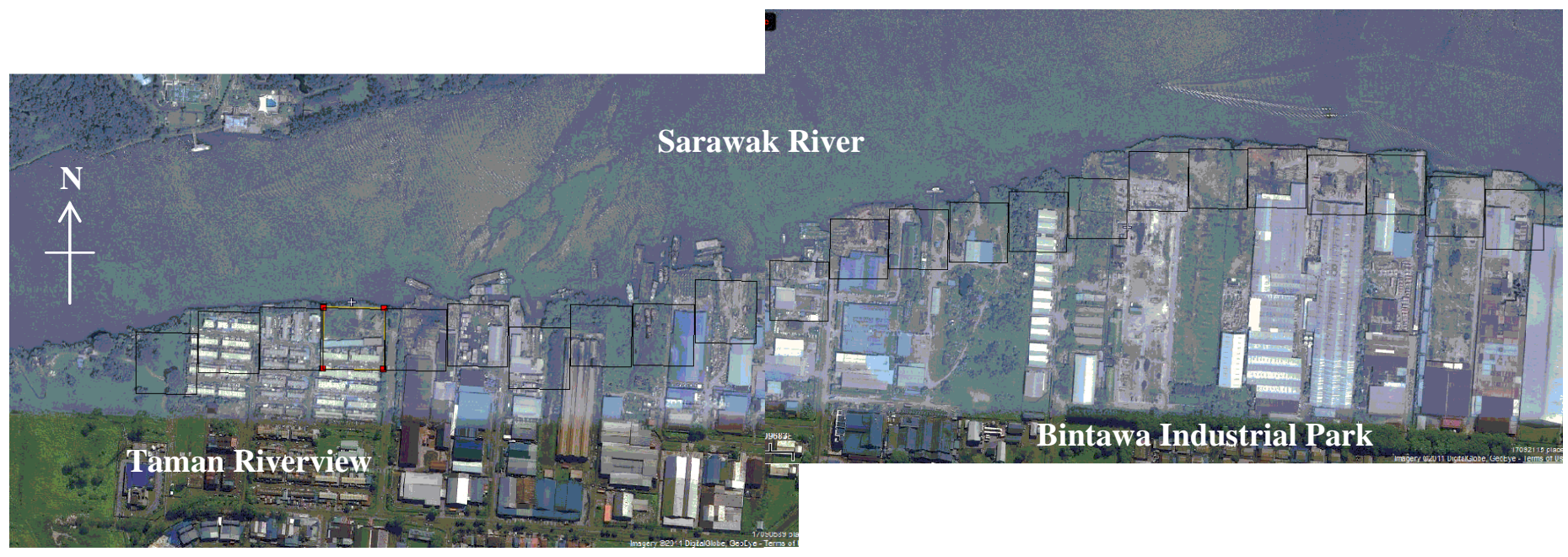

Figure 2: Study Area with Delineated Sampling Plots

\section{RESULTS AND DISCUSSION}

\section{Observation at Site}

Bintawa is a mixed-use area comprising factories, garages and residential houses. Most of the industrial establishments are constructed with riverside embankments and jetties along the riverbank of Sarawak River, as shown in Figure 3 . These developments have negatively affected the natural riparian zone. The soil type of the riverbank is naturally peat soil. However, the construction of embankments with building materials such as concrete, stone, and timber has changed the soil characteristics.

The native vegetation consists of coconut palms, nipah palms, areca, and sago palms [8]. Most of the native vegetation has been destroyed by human activities. However, healthy small trees, shrubs and grasses are found along the riparian zone, as shown in Figure 4. These plants are periodically maintained by the City Council. The observed vegetation species are physiologically adapted to a greater amount of groundwater compared with the upland species [9],[10]. The well-being of the riparian zone is perceived to be relatively straightforward given the lushness of vegetation growth in the tropical environment, as demonstrated through the stark contrast between the bare grounds in Figure 3 and the greenery in Figure 4 .

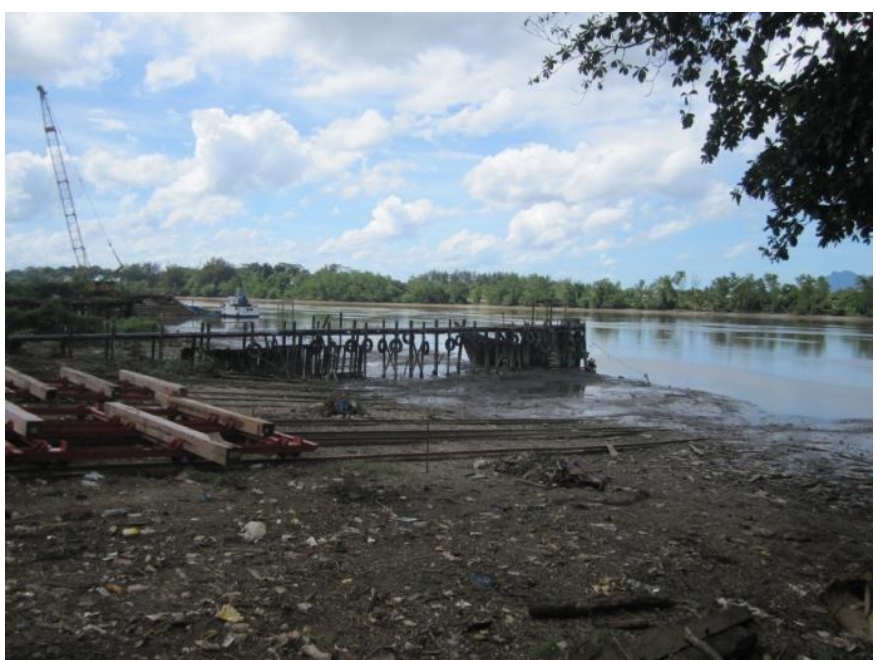

Figure 3: Jetties and Riverbank Conditions in Bintawa

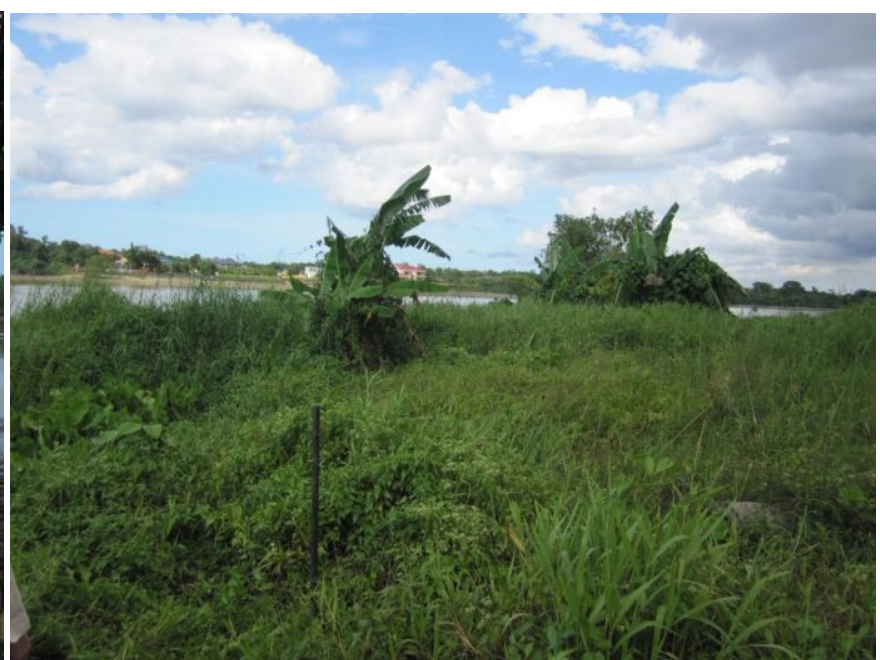

Figure 4: Common Vegetation in the Study Area 


\section{Riparian Health Status}

Vegetation plays a major role in the proper functioning of a riparian zone [11]. Removing vegetation from stream banks can decrease bank stability and lead to increased soil erosion. Rapid bank erosion can slow down plant establishment, leading to a problematic feedback loop of riparian degradation [12]. One such disturbance to a riparian zone is the lowering of groundwater tables and subsequent compaction of riparian soils [13]. These form the basis of assessing the riparian health along the selected Sarawak Riverbank.

The assessment of the riparian health consists of four elements, which are growth of trees, shrubs or grasses; erosion of stream banks; vegetation removal; and soil compaction. The in-field observations of the riparian conditions are summarised in Table 1. Riparian health is categorised into three classifications: functioning, intermediate functioning, and nonfunctioning. Based on the site investigations, the riparian zone at Bintawa is generally classified as intermediate functioning.

Table 1: Riparian Health Status according to Sampling Plots

\begin{tabular}{|c|c|c|c|c|c|}
\hline Plot & $\begin{array}{c}\text { Growth of } \\
\text { Trees, Shrubs, } \\
\text { or Grasses }\end{array}$ & $\begin{array}{c}\text { Erosion of } \\
\text { the Stream } \\
\text { Banks }\end{array}$ & $\begin{array}{l}\text { Vegetation } \\
\text { Removal }\end{array}$ & $\begin{array}{c}\text { Soil } \\
\text { Compaction }\end{array}$ & $\begin{array}{l}\text { Riparian Health } \\
\text { Status }\end{array}$ \\
\hline 1 & $\sqrt{ }$ & & & $\sqrt{ }$ & Intermediate \\
\hline 2 & & $\sqrt{ }$ & $\sqrt{ }$ & $\sqrt{ }$ & Non-functioning \\
\hline 3 & & $\sqrt{ }$ & $\sqrt{ }$ & $\sqrt{ }$ & Non-functioning \\
\hline 4 & $\sqrt{ }$ & & & $\sqrt{ }$ & Intermediate \\
\hline 5 & $\sqrt{ }$ & & & $\sqrt{ }$ & Functioning \\
\hline 6 & & $\sqrt{ }$ & $\sqrt{ }$ & $\sqrt{ }$ & Non-functioning \\
\hline 7 & & & $\sqrt{ }$ & $\sqrt{ }$ & Intermediate \\
\hline 8 & $\sqrt{ }$ & $\sqrt{ }$ & & $\sqrt{ }$ & Intermediate \\
\hline 9 & $\sqrt{ }$ & $\sqrt{ }$ & & $\sqrt{ }$ & Intermediate \\
\hline 10 & $\sqrt{ }$ & $\sqrt{ }$ & & $\sqrt{ }$ & Intermediate \\
\hline 11 & & $\sqrt{ }$ & $\sqrt{ }$ & $\sqrt{ }$ & Non-functioning \\
\hline 12 & & & $\sqrt{ }$ & $\sqrt{ }$ & Intermediate \\
\hline 13 & $\sqrt{ }$ & $\sqrt{ }$ & & $\sqrt{ }$ & Intermediate \\
\hline 14 & $\sqrt{ }$ & & & $\sqrt{ }$ & Functioning \\
\hline 15 & $\sqrt{ }$ & & & $\sqrt{ }$ & Intermediate \\
\hline 16 & $\sqrt{ }$ & $\sqrt{ }$ & & $\sqrt{ }$ & Intermediate \\
\hline 17 & & & $\sqrt{ }$ & $\sqrt{ }$ & Intermediate \\
\hline 18 & $\sqrt{ }$ & & & $\sqrt{ }$ & Functioning \\
\hline 19 & $\sqrt{ }$ & $\sqrt{ }$ & & $\sqrt{ }$ & Intermediate \\
\hline 20 & & & $\sqrt{ }$ & $\sqrt{ }$ & Intermediate \\
\hline 21 & $\sqrt{ }$ & $\sqrt{ }$ & & $\sqrt{ }$ & Functioning \\
\hline 22 & $\sqrt{ }$ & & & $\sqrt{ }$ & Functioning \\
\hline 23 & & & $\sqrt{ }$ & $\sqrt{ }$ & Intermediate \\
\hline
\end{tabular}

\section{Vegetation Cover}

Vegetation is a reliable indicator of riparian health due to its relative permanence. Its lushness reflects the nature of underlying soils, local climate, current and past management; it is also the medium in which animals live and feed [14],[15]. The extent of vegetation cover is shown in Figure 5, which has been digitised through ESRI ArcView GIS. Numbering of the plots is shown in the same figure. A summary of their respective areas and percentages of coverage is listed in Table 2.

\section{Human Activities}

Human activities influence the composition and integrity of riparian vegetation. The principal culprits are industrial and urban developments, with their attendant problems of pollution and disturbance. Human footprint on a riparian zone is measured to provide confirmation of its impacts and early warnings of the effects of excessive human or management pressure [14]. The coverage of human activities is shown in Figure 6. Plot 6 has the highest percentage of human activities, which is $91.82 \%$ of the total area, as shown in Table 3.

There will be discussions on the implications of the measured coverage of vegetation and human activities in subsequent research papers. Generally, there are some human activities and vegetation at the site. Coverage of vegetation is inversely proportional to the coverage of human activities. As such, it provides a convenient and simple tool to guide the planning and designing stage of land uses in riverbank developments. 


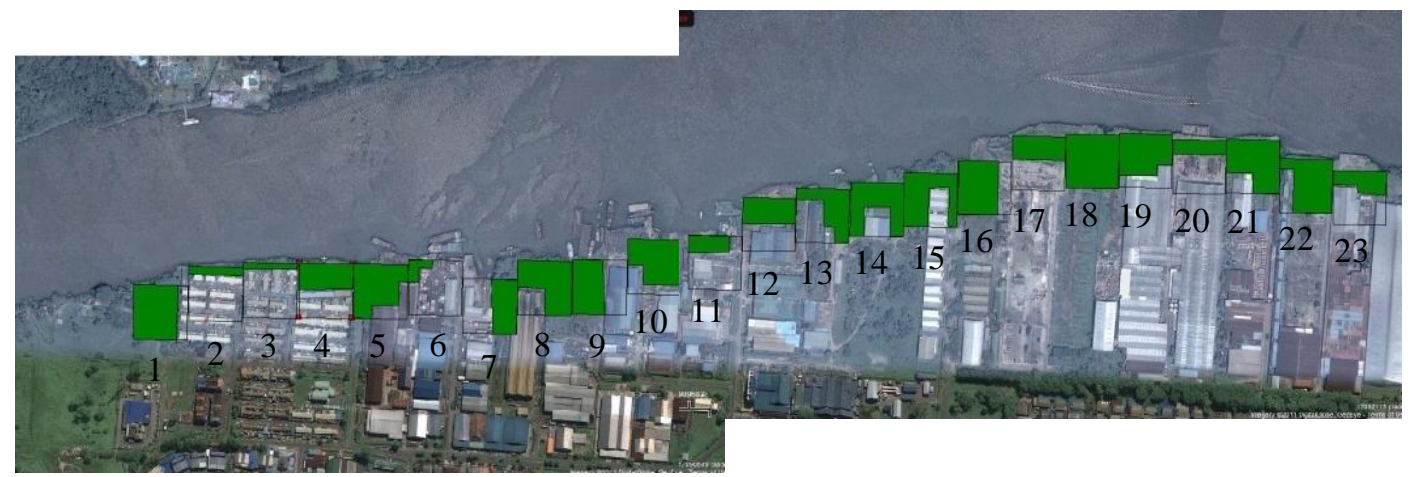

Figure 5: Coverage of Vegetation Cover

Table 2: Area and Percentage of Coverage for Vegetation Cover

\begin{tabular}{|c|c|c|}
\hline Plot & $\begin{array}{c}\text { Vegetation } \\
\left.\text { Area } \mathbf{( m}^{\mathbf{2}}\right)\end{array}$ & $\begin{array}{c}\text { Percentage of } \\
\text { Vegetation }(\boldsymbol{\%})\end{array}$ \\
\hline 1 & 8019.0 & 80.2 \\
\hline 2 & 1539.3 & 15.4 \\
\hline 3 & 1005.6 & 10.1 \\
\hline 4 & 4610.6 & 46.1 \\
\hline 5 & 8214.2 & 82.1 \\
\hline 6 & 817.6 & 8.1 \\
\hline 7 & 4370.2 & 43.7 \\
\hline 8 & 7978.2 & 79.8 \\
\hline 9 & 5892.9 & 58.9 \\
\hline 10 & 7715.4 & 77.1 \\
\hline 11 & 1913.3 & 19.1 \\
\hline 12 & 4770.5 & 47.7 \\
\hline
\end{tabular}

\begin{tabular}{|c|c|c|}
\hline 12 & 4770.5 & 47.7 \\
\hline 13 & 6339.4 & 63.4 \\
\hline 14 & 8316.6 & 83.2 \\
\hline 15 & 7963.5 & 79.6 \\
\hline 16 & 7571.3 & 75.7 \\
\hline 17 & 4419.0 & 44.2 \\
\hline 18 & 10000.0 & 100.0 \\
\hline 19 & 6639.6 & 66.4 \\
\hline 20 & 2669.8 & 26.7 \\
\hline 21 & 8702.8 & 87.0 \\
\hline 22 & 8797.4 & 88.0 \\
\hline 23 & 3766.6 & 37.7 \\
\hline & Average & $\mathbf{5 7 . 4}$ \\
\hline
\end{tabular}

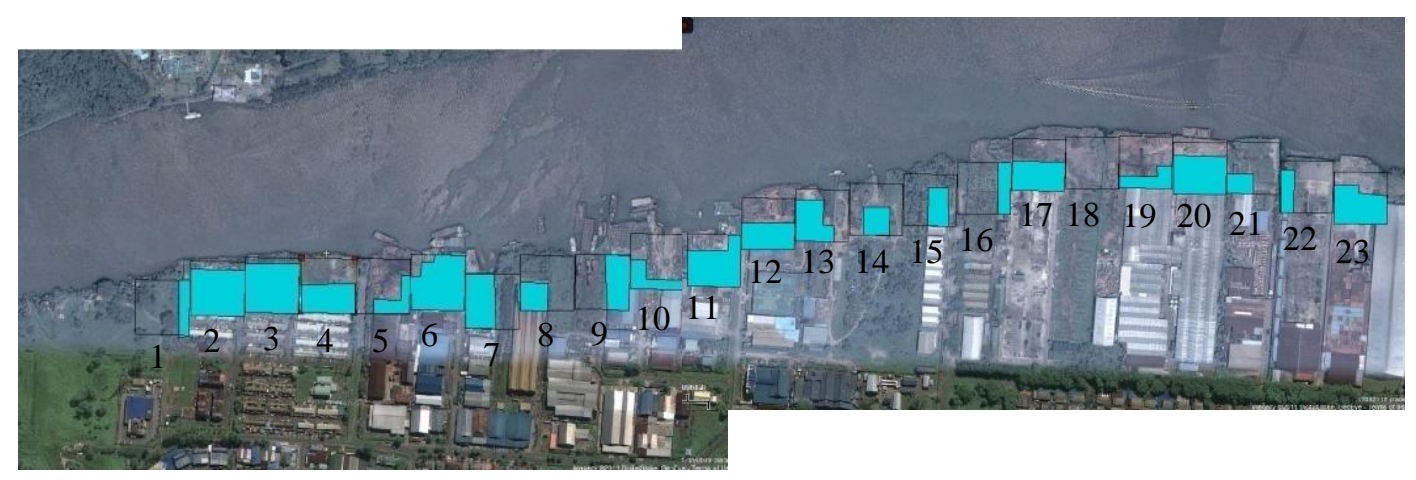

Figure 6: Coverage of Human Activities

Table 3: Area and Percentage of Coverage for Human Activities

\begin{tabular}{|c|c|c|}
\hline Plot & $\begin{array}{c}\text { Human } \\
\text { Disturbance } \\
\left.\text { Area } \mathbf{( m}^{\mathbf{2}}\right)\end{array}$ & $\begin{array}{c}\text { Percentage of } \\
\text { Human } \\
\text { Activities } \mathbf{( \% )}\end{array}$ \\
\hline 1 & 1981.0 & 19.8 \\
\hline 2 & 8460.7 & 84.6 \\
\hline 3 & 8994.4 & 89.9 \\
\hline 4 & 5389.4 & 53.9 \\
\hline 5 & 1785.8 & 17.9 \\
\hline 6 & 9182.4 & 91.8 \\
\hline 7 & 5629.8 & 56.3 \\
\hline 8 & 2021.8 & 20.2 \\
\hline 9 & 4107.1 & 41.1 \\
\hline 10 & 2284.6 & 22.9 \\
\hline 11 & 8086.7 & 80.9 \\
\hline
\end{tabular}

\begin{tabular}{|c|c|c|}
\hline 12 & 5229.5 & 52.3 \\
\hline 13 & 3660.6 & 36.6 \\
\hline 14 & 1683.4 & 16.8 \\
\hline 15 & 2036.5 & 20.4 \\
\hline 16 & 2428.7 & 24.3 \\
\hline 17 & 5581.0 & 55.8 \\
\hline 18 & 0.0 & 0.0 \\
\hline 19 & 3360.4 & 33.6 \\
\hline 20 & 7330.2 & 73.3 \\
\hline 21 & 1297.2 & 13.0 \\
\hline 22 & 1202.6 & 12.0 \\
\hline 23 & 6233.4 & 62.3 \\
\hline & Average & $\mathbf{4 2 . 6}$ \\
\hline
\end{tabular}




\section{Groundwater Level}

In most undisturbed watersheds, water flows naturally into riparian zones and streams as groundwater rather than runoff. A healthy riparian zone has high water table and high storage capacity. Hence, an indication of groundwater table is an effective tool to manage appropriate actions when required, in order to mitigate the adverse impacts on the riparian ecosystems that are groundwater dependent [16], [17]. Observations of soil characteristics along the river edge are important to determine the groundwater level for every plot. This qualitative groundwater assessment is tabulated in Table 4.

Table 4: Groundwater Conditions according to Sampling Plots

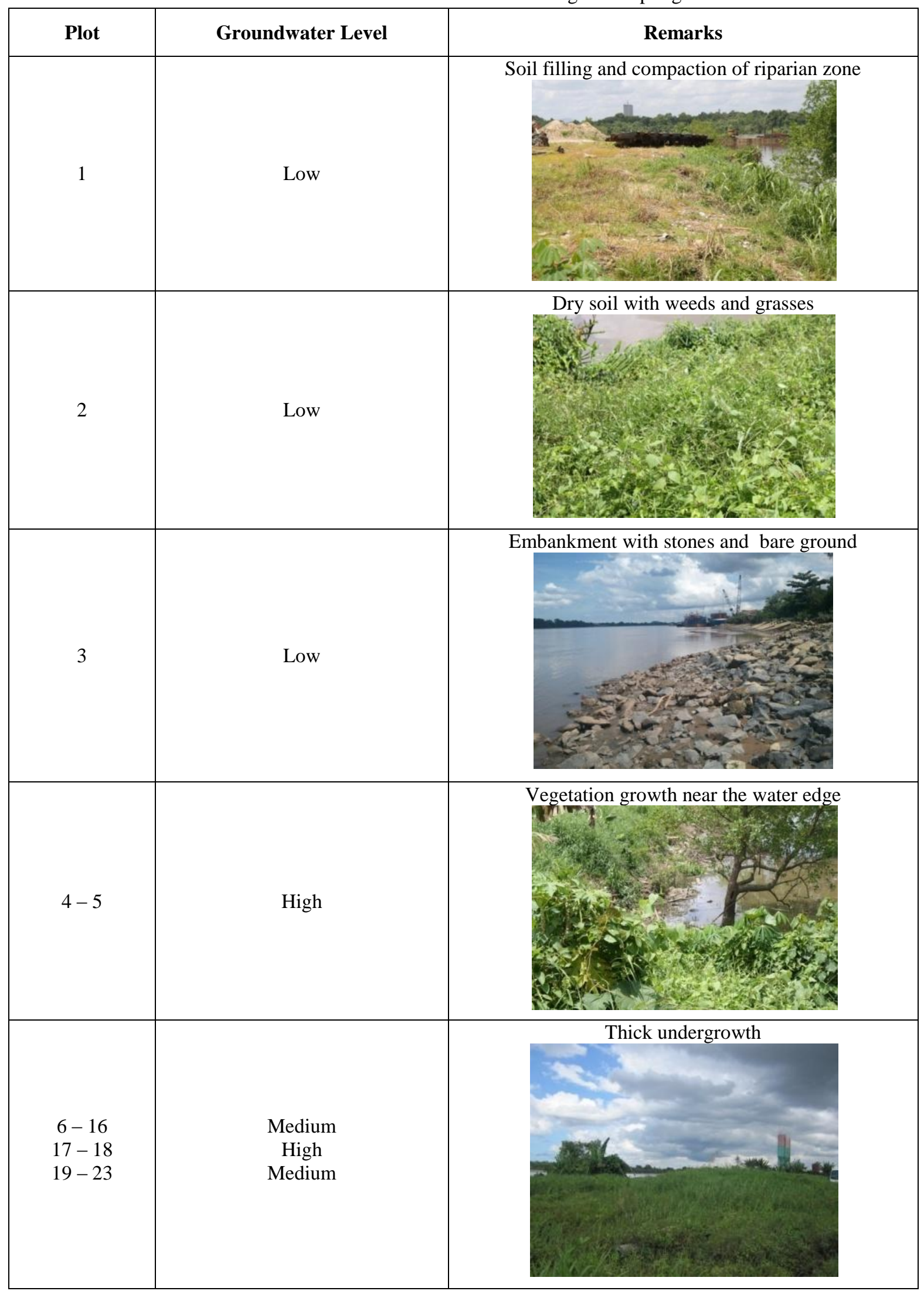




\section{Anthropogenic Implications}

To detail the riparian conditions, riparian health statuses of the respective plots in Bintawa are shown in Table 5 by ranking them in accordance with the associated percentage of human activities, from low to high. Hence, with the available statistics and functionality of the riparian zone, it is evident the three attributors - human activities, vegetation cover and groundwater table, provide an overall indication of human impacts on riparian conditions.

Table 5: Indicators of Human Activities to Riparian Health

\begin{tabular}{|c|c|c|c|c|c|}
\hline $\begin{array}{c}\text { Human } \\
\text { Activities } \\
(\%)\end{array}$ & $\begin{array}{c}\text { Vegetation } \\
\text { Cover } \\
(\%)\end{array}$ & $\begin{array}{c}\text { Groundwater } \\
\text { Level }\end{array}$ & Plot & $\begin{array}{c}\text { Riparian Health } \\
\text { Status }\end{array}$ & Remarks \\
\hline 0.0 & 100.0 & High & 18 & Functioning & \\
\hline 12.0 & 88.0 & Medium & 22 & Functioning & Mean $12 \%$ of \\
\hline 13.0 & 87.0 & Medium & 21 & Functioning & Human Activities \\
\hline 16.8 & 83.2 & Medium & 14 & Functioning & \\
\hline 17.9 & 82.1 & High & 5 & Functioning & Desirable Range \\
\hline 19.8 & 80.2 & Low & 1 & Intermediate & 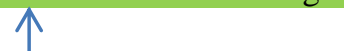 \\
\hline 20.2 & 79.8 & Medium & 8 & Intermediate & \\
\hline 20.4 & 79.6 & Medium & 15 & Intermediate & Mean $25 \%$ of \\
\hline 22.9 & 77.1 & Medium & 10 & Intermediate & Human Activities \\
\hline 24.3 & 75.7 & Medium & 16 & Intermediate & \\
\hline 33.6 & 66.4 & Medium & 19 & Intermediate & Tolerable Range \\
\hline 36.6 & 63.4 & Medium & 13 & Intermediate & $\downarrow$ \\
\hline 41.1 & 58.9 & Medium & 9 & Intermediate & $\uparrow$ \\
\hline 52.3 & 47.7 & Medium & 12 & Intermediate & \\
\hline 53.9 & 46.1 & High & 4 & Intermediate & \\
\hline 55.8 & 44.2 & High & 17 & Intermediate & \\
\hline 56.3 & 43.7 & Medium & 7 & Intermediate & \\
\hline 62.3 & 37.7 & Medium & 23 & Intermediate & \\
\hline 73.3 & 26.7 & Medium & 20 & Intermediate & Mean $67 \%$ of \\
\hline 80.9 & 19.1 & Medium & 11 & Non- functioning & Human Activities \\
\hline 84.6 & 15.4 & Low & 2 & Non- functioning & \\
\hline 89.9 & 10.1 & Low & 3 & Non- functioning & Destructive Range \\
\hline 91.8 & 8.2 & Medium & 6 & Non- functioning & 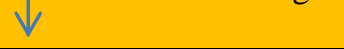 \\
\hline
\end{tabular}

From the table above, the impacts of human activities on the riparian health can be divided into three categories. On the top (shaded with green), it is named "desirable range" of functioning riparian zone, with a mean of $12 \%$ human activities and the range is 0 to $17.9 \%$. In the middle is the "intermediate functioning" riparian zone, which can be sub-divided into upper half and lower half. Practically, it can be said the upper half is approaching the functioning category, and thus it is named "tolerable range", with a mean of $25 \%$ human activities. The lower half falls into the bottom category (shaded in orange) indicating "destructive range", with a mean of $67 \%$ human activities. Distribution of the three categories is shown in Figure 7.

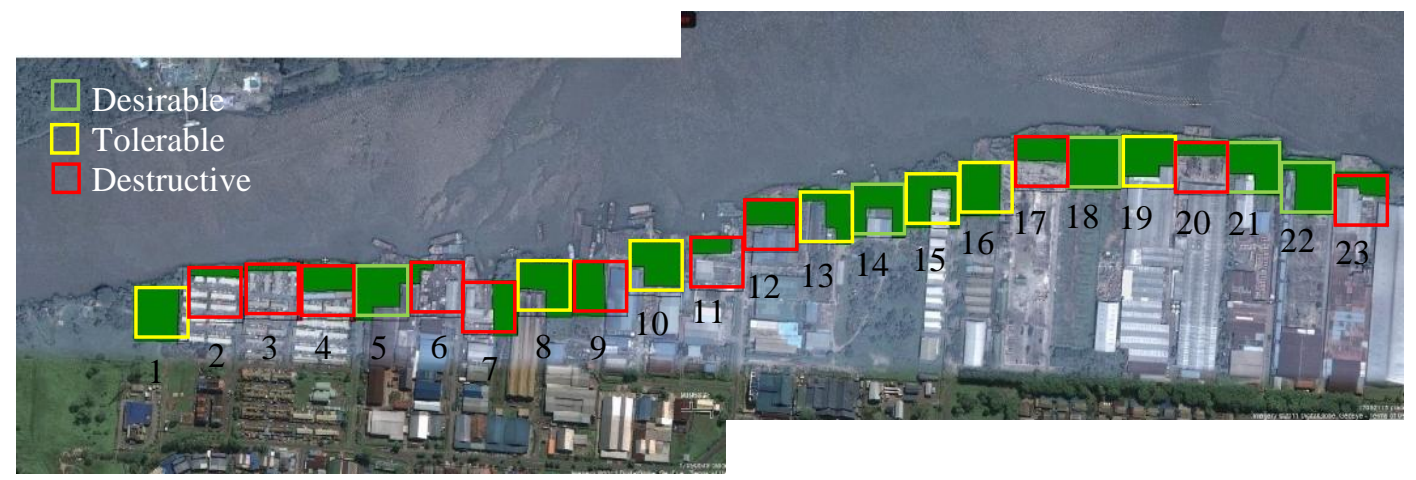

Figure 7: Distribution of Desirable, Tolerable and Destructive Plots

Based on the figure above, it is evident that a high percentage of vegetation cover indicates proper functioning of the related riparian zone. Presence of vegetation is one of the main characteristics of intact river corridors. The existence of continuous vegetated strips along the riverbank is an evidence of the continuous flow or movement of groundwater. The desirable and tolerable ranges have high and medium groundwater tables respectively, with the exception of Plot 1. 


\section{UNIMAS e-Journal of Civil Engineering}

\section{CONCLUSION AND RECOMMENDATIONS}

The tasks of delineating a field and carrying out an investigation regarding changes in the riparian zone are successful; the assessments of the human impacts on the riparian zone are duly completed. This study has been carried out at Bintawa beside the Sarawak River. Twenty-three plots of land are analysed for their riparian health based on indicators of human activities, vegetation cover and groundwater level. A healthy riparian zone should have a reasonable amount of human activities and vegetation as well as high groundwater level.

The overall riparian health of the study area is classified as "intermediate functioning". There are some indications of degraded ecosystems, leading to a change from aquatic to terrestrial system. Coverage of human activities and vegetation cover are determined with ESRI ArcView GIS while groundwater levels are assessed through field observations. From the analysis, it is best to keep a functioning riparian zone in the "desirable range" that has a mean of $12 \%$ human activities and the range is $0 \%$ to $17.86 \%$. It is found that a riparian zone can tolerate human disturbances up to a mean of $25 \%$ human activities.

As a recommendation, development land should be managed on the basis of true multiple uses. Developers or managers must recognise the biological potential of each ecological zone, and it is imperative for them to evaluate the present and future needs of our society. Resource values should be taken into account in designing management strategies, which will help maintain or restore the integrity of the riparian communities. Healthy riparian zones can be achieved through the balancing of human developments and nature conservation.

\section{REFERENCES}

[1] R.G. Wagner, and J.M. Hagan, Forestry and the Riparian Zone, Conference Proceedings, October 26, Wells Conference Center, University of Maine, Orono Maine, 2000.

[2] E.T. Machtinger, Riparian Systems, Washington, DC: Natural Resources Conservation Service, 2007.

[3] R.E. Warner, and K.M. Hendrix, California Riparian Systems: Ecology, Conservation and Productive Management, Berkeley: University of California Press, 1984.

[4] H. Shear, N. Stadler-Salt, P. Bertram, and P. Horvatin, "The development and implementation of indicators of ecosystem health in the Great Lakes basin", Environmental Monitoring and Assessment, 88, 119-152, 2003.

[5] M.Z. Rozainah, and N. Aslezaeim, "A demographic study of a mangrove palm, Nypa fruticans", Scientific Research and Essay, 5 (24), 3896-3902, 2010.

[6] C. Wolff, L. Guo, and S. Smorodinsky, Geographic Information System (GIS), California Department of Public Health, 2010.

[7] M. Eusuff, A. Helwa, K. Lansey, "Restoration of riparian zones - a decision support system", Integrated Surface and Ground Water Management 312-320, 2001. Doi:10.1061/40562(267)33

[8] D.Y.S. Mah, and K.K.K. Kouk, "Field investigation on anthropogenic impacted lowland riparian zone", Journal of Water Resources and Protection, $5,259-265,2013$.

[9] C.N. Goodwin, C.P. Hawkins, and J.L. Kershner, "Riparian restoration in the Western United States: overview and perspective", Restoration Ecology, 5 (4 Suppl.), 4-14, 1997.

[10] P.M. Groffman, "Down by the riverside: urban riparian ecology", Frontiers in Ecology and Environment, 1, 315-321, 2003.

[11] W.S. Platts, G.L. Armour, G.D. Booth, M. Bryant, J.L. Bufford, P. Cuplin, S. Jensen, G.W. Lienkaemper, G.W. Minshall, S.T. Monsen, R.L. Nelson, J.R. Sedell, and J.S. Tuhy, Methods for Evaluating Riparian Habitats with Applications to Management, General Technical Report INT-221, Ogden, UT: USDA Forest Service, 1987.

[12] H. Décamps, M. Fortune, F. Gazelle, and G. Patou, "Historical influence of man on the riparian dynamics of fluvial landscape", Landscape Ecology, $1,163-173,1988$.

[13] C.T. Hammersmark, M.C. Rains, A.C. Wickland, and J.F. Mount, "Vegetable and water-table relationship in a hydrologically restored riparian meadow", The Society of Wetland Scientists, 29, 785-797, 2009.

[14] F.B. Goldsmith, Monitoring for Conservation and Ecology, First Edition, London: Chapman and Hallo, 1991

[15] D.N. Pennington, J.R. Hansel, and D.L. Gorchov, "Urbanization and riparian forest woody communities: diversity, composition, and structure within a metropolitan landscape", Biological Conservation, 143, 182-194, 2010.

[16] J.C. Stromberg, "Freemont Cottonwood - Goodding Willow riparian forests: a review of their ecology, threats and recovery potential", Journal of the Arizona-Nevada Academy of Science, 27, 97-110, 1993

[17] E. Tabacchi, L. Lambs, H. Guilloy, A-M. Planty-Tabacchi, E. Muller, and H. Décamps, "Impacts of riparian vegetation on hydrological processes", Hydrological Processes, 14 (16-17), 2959-2976, 2000. 